Original Article

\title{
ANTAGONISTIC EFFECT OF MUSK ON ORGANISMS DIFFERENT TYPES
}

\author{
JANA ABDUL MOHSEN ALJURISS ${ }^{1}$, NOURA SAUD ALNAJEM"1 ${ }^{1}$ FAHDAH FAHAD ALGHOFAILI ${ }^{1}$, AMAL A. AL- \\ MOUSA $^{2}$, TURKI N. AL-ARIFI ${ }^{3}$, FATIMAH S. AL-KHATTAF ${ }^{4}$
}

${ }^{1}$ Botany and Microbiology Department, Students of College of Sciences, King Saud University, Riyadh,12824, Saudi Arabia, 2,4Botany and Microbiology Department, Faculty of College of Sciences, King Saud University, ${ }^{3}$ Department of Bacteriology, Laboratory Specialist of Regional Laboratory and Blood Bank, King Saud Medical City

Email: 435200403@student.ksu.edu.sa

Received: 13 Jun 2020, Revised and Accepted: 16 Aug 2020

\begin{abstract}
Objective: This study aims to The research aimed at a comparative study the effect of natural and synthetic musk compared to creams that have an anti-fungal and anti-bacterial effect on the growth of Candida albicans that causes vaginal diseases in women, as well as the growth of the bacteria strains include Staphylococcus aureus, Bacillus subtilis, which would be more effective in inhibiting the growth of these microbes and Achieve the recommendation of the Prophet Muhammad for women to treat the vagina with natural musk, find alternatives to synthetic antibiotics, and reduce their negative effects on human health.

Methods: This study investigates the antagonistic effect of Anti fungal and bacterial Cream and different natural type \{Musk (N. M), Black Musk (B. M)\} and chemical Musk \{white Musk (W. M), cream Musk (M. C) \} on some microorganisms. The types of yeast Candida albicans HVS and the bacteria strains include Staphylococcus aureus, Bacillus subtilis, were tested by means of disk diffusion,

Results: Results indicated that Musk has inhibitory effects on the growth of study microorganisms Musk contains active substances similar to antibiotic, alkaloids and volatile oils present in them as they have the ability to stop the growth of many microorganisms. The effect of natural musk was higher than the effect synthetic musk, And the microbes were the most sensitive to musk is Bacillus subtilis. As for anti-microbial creams, the effect of the anti-bacterial cream was more effective in their suppression compared to all kinds of musk unlike the anti-fungal cream which gave a negative result.
\end{abstract}

Conclusion: This study showed that the different concentrations of natural musk have an effective role in inhibiting some of the microbes of this vaginal pathogen, and it has given a positive opposite result to these microbes, and therefore it can be used as a natural antibiotic that reduces side effects on females and the environment.

Keywords: Musk, Microorganisms, Antagonistic, Pathogenic

(C) 2020 The Authors. Published by Innovare Academic Sciences Pvt Ltd. This is an open access article under the CC BY license (http://creativecommons.org/licenses/by/4.0/) DOI: http://dx.doi.org/10.22159/ijcpr.2020v12i5.39777. Journal homepage: https://innovareacademics.in/journals/index.php/ijcpr

\section{INTRODUCTION}

Antimicrobial resistance refers to the evolutionary capacity developed by microorganisms such as bacteria, fungi and parasites to fight and neutralize an antimicrobial agent. According to the World Health Organization [1], the optimism of the early period of antimicrobial discovery has been tempered by the emergence of bacterial strains with resistance to this therapeutics. Today, clinically important bacteria are characterized not only by single drug resistance but also by multiple antibiotic resistances, the legacy of past decades of antimicrobial use and misuse. Drug resistance presents an ever-increasing global public health threat that involves all major microbial pathogens and antimicrobial drugs. The number of pathogens presenting multidrug resistance has had an exponential increase in recent times and is considered an important problem for public health Chemical treatment of these diseases by antibiotics has its side effects on human health, in addition to the possible development of resistant microbial strains which may cause various problems [2]

Because of the side effects and the resistance that pathogenic microorganisms build against the antibiotics, therefore, it is worthwhile to look for an alternative cure such as extract biological active compounds from plants species that used in herbal medicine [3] or Musk [4-6]. Animal Musk is one of the natural substances. Many investigations were carried out to study the use of natural sources to inhibit the growth of many pathogenic microorganisms for human, animals and plants, Musk also proved more effective against the tested fungi more than Nystatin antibiotic [7]. Musk is formed of several compounds, the main compound which causes the odour is muscone (3-methylcyclopentadecan-one-1) the active ingredient of musk [8], has medicinal properties, Other compounds present in musk include steroids, paraffin, triglycerides, waxes, muco pyridine, other nitrogenous substances and fatty acids $[9,10]$. It has been long used in traditional medicine a sedative [8].

Musk has been used as a perfume since ancient times. "The name "musk" has encompassed a wide variety of substances with somewhat similar odours although many of them are quite different in their chemical structures" [11]. This includes artificial substances such as castoreum, platinum, crocus, amber and valerian with similar odours which at present are the ones that are used almost exclusively [12]. Natural musk has an inhibitory effect due to its composites and metabolic yields such as alkaloids, flavonoids, sterols and antibiotics. These composites may disrupt bacterial and fungal cells through raising the permeability of cell membranes causing leak important substances that led to cell death. Also, it may inhibit the microbes by preventing the synthesis of nucleic acids causing the construction of abnormal proteins. Volatile oils in musk could be the reason for its inhibitory effect $[13,14]$. This study aims to investigate the antagonistic effect of Musk as a natural and chemical score on different type's organisms. The previous study has shown that musk has a fungi static fungicidal, parasitotic, bactericidal and bacteriostatic effect [7]. Musk is known to have been used in medicine and as a fragrance since 3500 BC. The musk scent was thought to have been used in the early civilizations of ancient China and ancient India in ritual purposes [15].

Musk is currently used for expensive perfume all over the world and for traditional medicine in oriental countries, has medicinal properties, It has been long used in traditional medicine a sedative and $[10,16,17]$, stimulant of the heart, nerves, breathing, sexual in 
resuscitation and refreshment, promoting blood flow and clearing channels, detumescence and alleviating pain [18]. It is also thought to be effective against snake venom and as an anti-inflammatory agent and to treat a variety of ailments $[19,20]$, the musk, many investigations were carried out to study the use of musk to inhibit the growth of many pathogenic microorganisms for human, animals and plants [21] mentioned that $25 \%$ of musk gave the highest percentage of suppression of biomass for each of A. niger, $F$. oxysporum and C. albicans [4].

Reported the ability of musk to inhibit the growth of Penicillium puberulum fungus. Saddiq and Kalifa, (2011) [14] proved the effectiveness of musk and sider extract in treating renal mycotoxicity, AL-Jobori et al., (2014) [6] reported that musk has inhibitory effects on the growth of Cryptococcus neoformans, Candida albicans and Saccharomyces cerevisiae, results also showed that the musk was more effective than antibiotics. Badawy et al., (2014) [5] mentioned that Musk is a safe natural product having the privilege of being anti Trichomonas vaginalis as well as an antifungal [22]

Staphylococcus aureus is one of the dangerous pathogenic bacteria that lived mainly in nasal membranes and skins of human or animals causing inflammations, blisters, sources as well as complication of acute wounds and burns resulting in inflammation of urinary tract ear, eye and blood sepsis [23]. Some of the yeasts also cause skin lesions such as Candida albicans which live and found in the gut, mouth and vagina and cause diseases in case of natural immune deficiency. It also infects nails and changes its color to yellowishgreen or dark [24]. The research aimed at a comparative study the effect of natural and synthetic musk compared to creams that have an anti-fungal and anti-bacterial effect on the growth of Candida albicans that causes vaginal diseases in women, as well as the growth of the bacteria strains include Staphylococcus aureus, Bacillus subtilis, which would be more effective in inhibiting the growth of these microbes.

\section{MATERIALS AND METHODS}

\section{Materials}

\section{Musk}

Natural Musk (N. M), Black Musk (B. M), white Musk (W. M).

\section{Microorganism strains}

Candida albicans HVS 2380 and Staphylococcus aureus was obtained from Regional Laboratory, King Saud Medical City, Saudi Arabia, bacillus subtilis, Laboratory of King Khalid University Hospital, Saudi Arabia. They were incubated at $37^{\circ} \mathrm{C}$

\section{Media}

Mueller-Hinton agar (MHA) were used as a base medium for a screening of antibacterial activity, and Sabouraud dextrose agar (SDA) while was used for yeast. The media was previously prepared/liter distilled water, then sterilized it in wet sterilization by autoclave at $15 \mathrm{~L} / \mathrm{square}$ inch for $20 \mathrm{~min}$.

\section{Methods}

\section{Experimental study in vitro}

The experimental study in vitro for screening bacterial and yeast activity was carried out according to the agar disc diffusion method; The (MHA for bacteria) and (SDA for yeast). The CLSI document M44 guidelines for antifungal disk diffusion susceptibility testing, disk diffusion method (Kirby-Bauer method). The principle used here is that Musk will diffuse from a paper disc $(1 \mathrm{~cm})$ into an agar medium (Muller Hinton agar) culture s. aureus and B. subtilis. Auther media SabrudDecstos Agar (SDA) that contains test organisms: (C. albican 2380). Serial dilution a serial dilution was prepared for all musk species. For each type, 4 were prepared with varying concentrations (25\%, 50\%, 75\%, 100\%) A solution (Dimethyl sulfoxide "DMSO") was used as a solvent for musk oil. $25 \%$ concentration was placed (2) $\mathrm{ml}$ of distilled water and (2) ml of musk Added $(0.5 \mathrm{ml})$ of solution $50 \%$ concentration was placed (2) $\mathrm{ml}$ of distilled water and

(2) ml of musk Added ( $1 \mathrm{ml}$ ) of DMSO solution $75 \%$ concentration was placed (2) ml of distilled water and (2) ml of musk Added (1.5 $\mathrm{ml}$ ) of DMSO solution.

\section{Procedure}

Make a subculture of the bacterial and candida to be tested. Place a sterile cotton swab in the bacterial subculture. The swab is streaked in over the surface of the Mueller-Hinton agar to obtain uniform growth. Place a sterile cotton swab in the candida subculture. The swab is streaked in over the surface of the Sabrud Decstos Agar to obtain uniform growth. Allow the plates to dry for five minutes. Using sterile forceps, place disks containing the following musk in the center plate.

\section{Incubation}

After overnight incubation, measures the diameter of the zone of growth inhibition around each disk to the nearest whole $\mathrm{mm}$ at 37 ${ }^{\circ} \mathrm{C}$ for 3 days (Odds, 1993). The activity of musk was determined by measuring the diameter of the inhibition zone around each plate by $(1 \mathrm{~cm})$.

\section{Screening of antibacterial and antiyeast activity}

Sabouraud dextrose Agar (SDA) (Merck Company) was used as base medium for screening of antifungal activity

\section{RESULTS}

\section{Linear growth}

Antagonistic effect of musk concentrations showed a more pronounced inhibitory effect on microorganism's strains. Clear halos were formed around the papers disk containing Musk and antibiotic creams. The linear growth of all microbes was measured for three days. we took on average three readings, as shown in tables 1,2.

Table 1: Effect of different concentrations of kinds of the musk (\%) of microbes after growing on media for $3 \mathrm{~d}$ at $37{ }^{\circ} \mathrm{C}$

\begin{tabular}{|c|c|c|c|c|c|c|c|c|c|c|c|c|c|}
\hline \multirow{3}{*}{$\begin{array}{l}\text { Name of the } \\
\text { microbes }\end{array}$} & \multicolumn{13}{|c|}{ Kinds of the musk } \\
\hline & \multirow{2}{*}{$\begin{array}{l}\text { Control } \\
0\end{array}$} & \multicolumn{4}{|c|}{ N. M I. Z (mm) } & \multicolumn{4}{|c|}{ B. M I. Z (mm) } & \multicolumn{4}{|c|}{ W. M I. Z (mm) } \\
\hline & & $25 \%$ & $50 \%$ & $75 \%$ & $100 \%$ & $25 \%$ & $50 \%$ & $75 \%$ & $100 \%$ & $25 \%$ & $50 \%$ & $75 \%$ & $100 \%$ \\
\hline C. albican & 0 & 0 & 0 & 0 & 0 & 0.75 & 1.6 & 1.8 & 2.2 & 0 & 0 & 0 & 1.3 \\
\hline B. subtilis & 0 & 0.2 & 0.5 & 0.9 & 1.7 & 1.4 & 1.4 & 1.5 & 1.8 & 0.4 & 0.5 & 0.7 & 1.2 \\
\hline S. aurus & 0 & 0.2 & 0.3 & 0.8 & 1.2 & 1.4 & 1.4 & 1.4 & 1.7 & 0.3 & 0.4 & 0.6 & 1.1 \\
\hline
\end{tabular}

N. M. Natural Musk, B. M. Black Musk, W. M. white Musk, I. Z. inhibition zone

Table 2: Effect of antibiotic creams of microbes after growing on media for $3 \mathrm{~d}$ at $37^{\circ} \mathrm{C}$

\begin{tabular}{llll}
\hline Name of the microbes & \multicolumn{3}{l}{ Antibiotic creams } \\
\hline & Control & Antifungal I. Z. (mm) & Antibacterial I. Z. (mm) \\
\hline C. albican & 0 & 0 & - \\
B. subtilis aurus & 0 & - & 3.4 \\
\end{tabular}


Table 3: The images of the inhibition zone of different musk $25 \%$ concentration on microbes

\begin{tabular}{|c|c|c|c|}
\hline \multirow{2}{*}{\multicolumn{2}{|c|}{$\begin{array}{ll} & \text { N. M. } \\
\text { C. albican }\end{array}$}} & \multirow{2}{*}{ B. M. } & \multirow[t]{2}{*}{ W. M. } \\
\hline & & & \\
\hline \multicolumn{4}{|l|}{ B. subtilis } \\
\hline \multicolumn{4}{|l|}{ S. aurus } \\
\hline
\end{tabular}

Table 4: The images of the inhibition zone of different musk $50 \%$ concentration on microbes

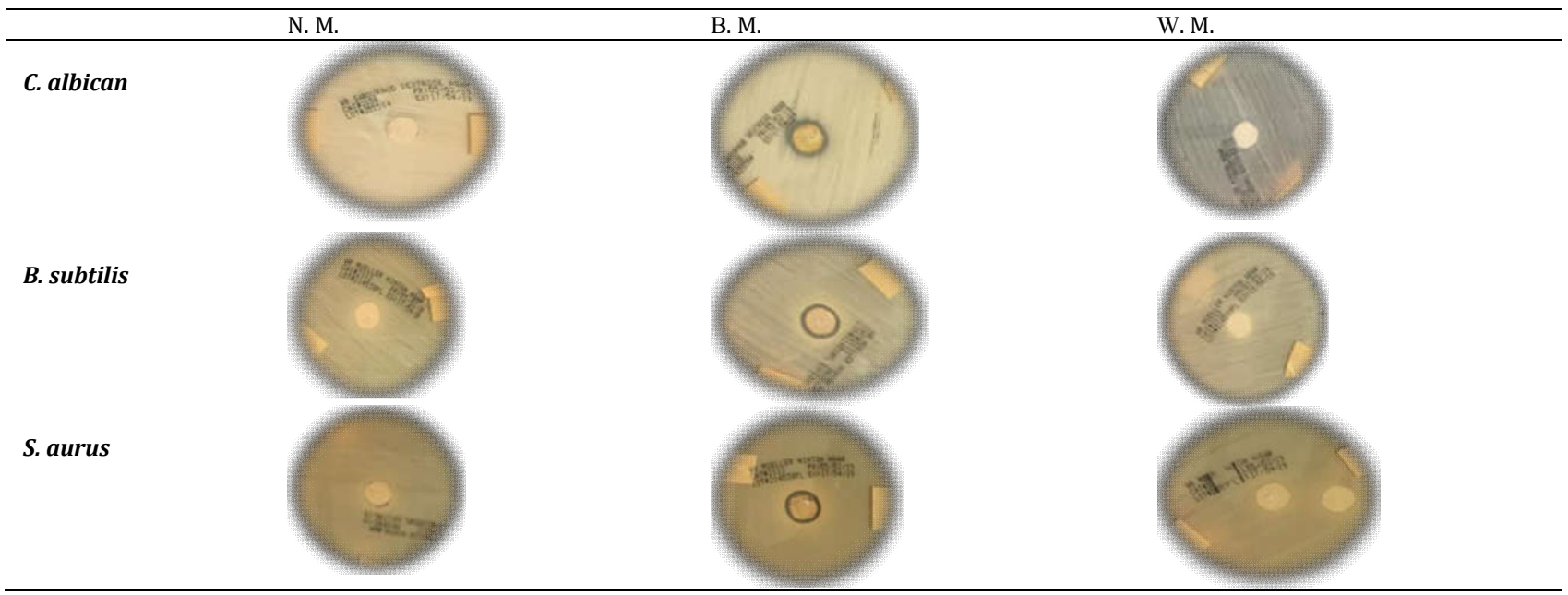

Table 5: The images of the inhibition zone of different musk 75\% concentration on microbes

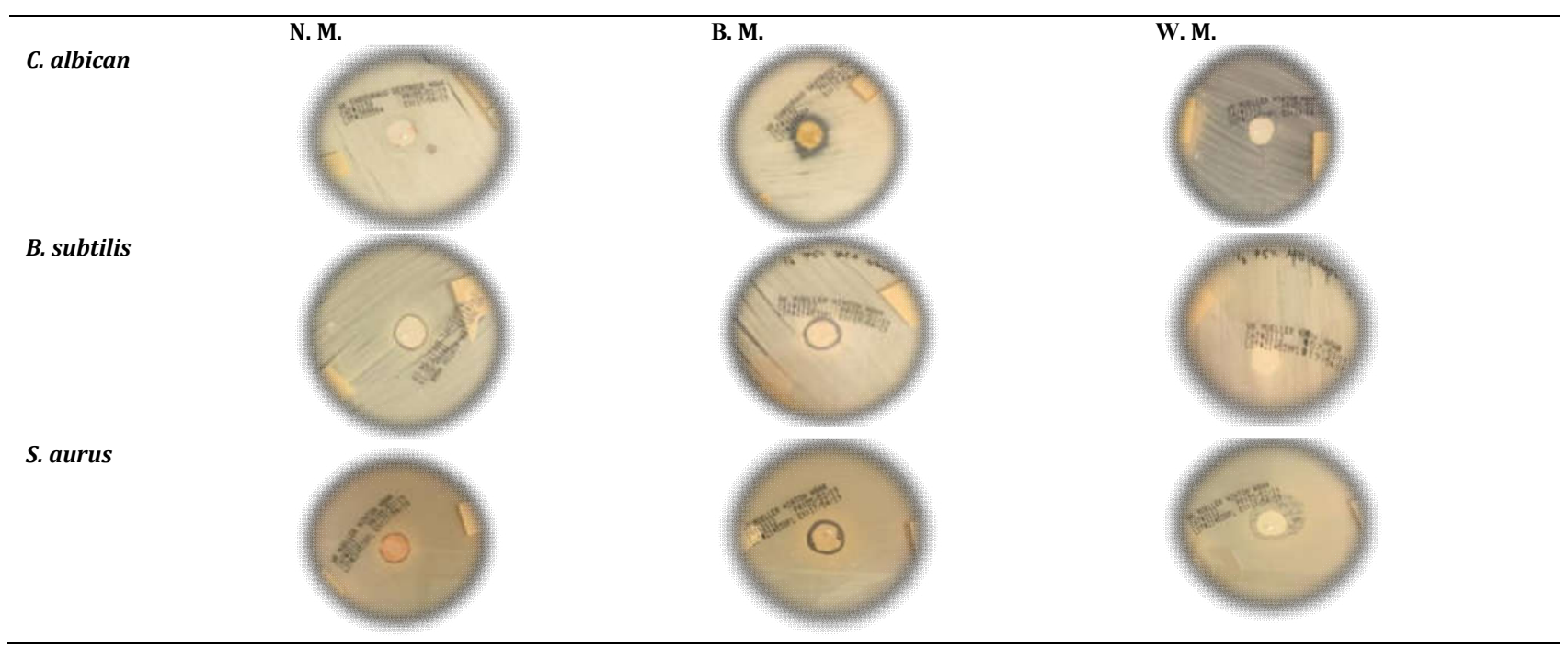


Table 5: The images of the inhibition zone of different antibiotic creams and musk $100 \%$ concentration on microbes

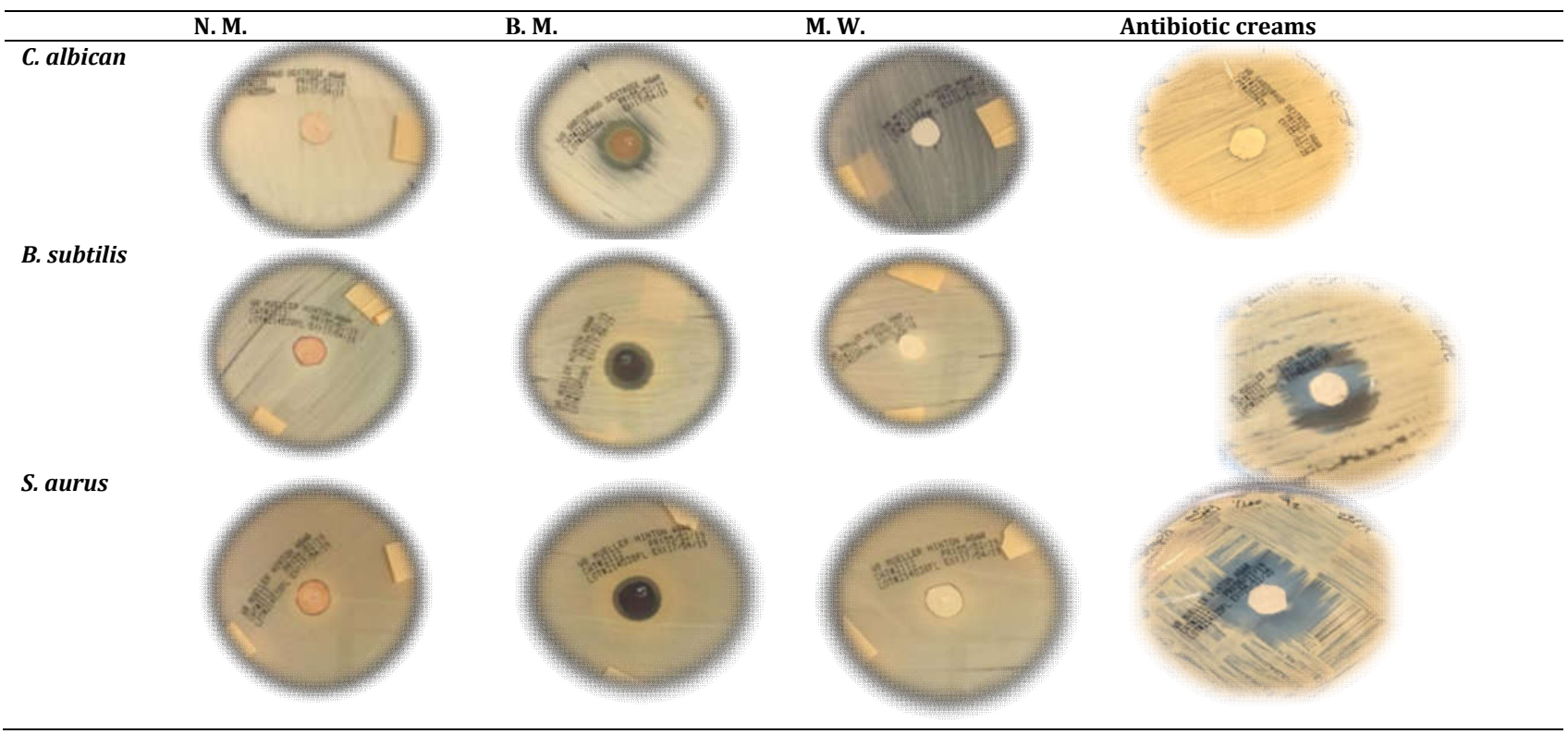

\section{DISCUSSION AND CONCLUSION}

This study is carried out to enhance the inhibition ability of natural and industrial Musk and evaluate the antagonistic effect of different concentrations of musk $(25,50,75$ and $100 \%)$ on some pathogenic microorganisms like $C$. albicans, $S$. aures, $B$. subtilis, the results of this study confirmed the effectiveness of natural and chemical musk which contains some of the active substances that have the inhibitory capacity of a wide range of microorganisms. Musk contains active substances similar to antibiotics, alkaloids and volatile oils present in them as they have the ability to stop the growth of many microorganisms [4]. These compounds may affect fungi cells through disrupting their membranes, thereby depriving the substrate or inactivating the enzymes. This leads to cell lysis and death. Cowan, (1999) [25] suggested that polyphenols act on the microbes by disrupting their membranes, depriving the substrate or inactivating the enzymes. Also, Musk extract compounds may inhibit the microorganisms through inhibiting the synthesis of nucleic acids resulting in the formation of abnormal proteins [26].

However, its inhibitory effect may be due to the presence of volatile oils, other authors Saddiq, (2014), Badawy et al., (2014) and Aljobori et al., (2014) [27, 5, 6] reported that musk has inhibitory effects on the growth of fungi. Musk had a great role in the suppression of the opportunistic fungal growth. Musk action can be caused by the chemical structure of musk as it contained muscone the active ingredient of musk [8], other compounds and metabolic products such as alkaloids, flavonoids, sterols and antibiotics which have a great effect as antimicrobial agents [28].

Highly volatile oils percentage and contain sterol hormones in which the most important was musk pyridine besides some enzymes that can elongate lag phase or affect mitotic divisions and elongate fungal cells acids. This is proven by the results of this study, shows the effect of different type of musk concentrations on microbes' types' growth. Musk (N. M) inC. albicans 2380, S. aureus (high resistant attributed the reason of this probably due to the fact that musk with high concentration $100 \%$ was less effective had high viscosity and caused cracks in the media, which impeded its spread through the media. Thebacteria (B. subtilis) is slightly sensitive because it is nonpathogen. The result is compared to a search [4]. Musk (B. M). In the yeast $C$. albicans 2380, high sensitive compared to the bacteria $S$. aureus and B. subtilisissensitive. Because musk action can be caused by the chemical structure of musk as, it contained muscone the active ingredient of musk [8].
Musk (W. M) (synthetic musk), several chemical compounds were manufactured as Musk alternatives since they have Musk-like smell though differ in the chemical formula of Musk[29]. In the B. subtilis high sensitive Compared to the $C$. albicans $2380, S$. aureus is slightly sensitive because synthetic musk it contains synthetic fragrance oil, limonene, flower blossom, herbs, spices.

Avocin Cream contains Clindamycin (Cleocin Phosphate) as an active ingredient. Clindamycin a semisynthetic bacteriostatic derivative of lincomycin,Lincosamide antibacterial that inhibits protein synthesis of the bacterial cell wall by binding to bacterial ribosomal receptor sites.(Shorr, R. I., Hoth, A. B., and Rawls, N.(2007) Lamifen Cream The active substance of the cream was weak compared to the results of musk and did not affect the vitality of the fungus. This indicates the severity of the resistance of the fungus to this active substance.

\section{RECOMMENDATION}

The musk can be used as a safe natural product in management and control of pathogenic microbes, so it provides a promising source for new drugs development.

\section{ACKNOWLEDGEMENT}

The authors would like to thank to the Deanship of Scientific Research at King Saud University for funding this work through the Undergraduate Research Support Program.

\section{FUNDING}

The authors extend their appreciation to the Deanship of Scientific Research at King Saud University for funding this work through the Undergraduate Research Support Program, Project no. (URSP -4 -1 -8 ).

\section{AUTHORS CONTRIBUTIONS}

Conceptualization J.M- N.N. and F.G; Methodology, J.M., N.N., F.G and A.M.; Diagnosis of microorganisms T.A., J.M., N.N. and F.G; Investigation, A.M; Writing-original draft preparation, J.M- N.N. and F.G.; Writing-review and editing, A.M. and F.K; Supervision, A.M.

\section{CONFLICT OF INTERESTS}

The authors declare no conflict of interest

\section{REFERENCES}

1. Leung E, Weil DE, Raviglione M, Nakatani H. The WHO policy package to combat antimicrobial resistance. Bulletin World Health Organization 2011;89:390-2. 
2. Black JG. Microbiology principles and application. Prentice Hall Inc 1996;3:563-55.

3. Hassawi D, Kharma A. Antimicrobial activity of some medicinal plants against candida albicans. J Biol Sci 2006; 6:109.

4. Saddiq AA. Potential effect of natural musk and probiotic on some pathogens strain. Int Res J Microbiol 2011;2:146-52.

5. Badawy AF, Elleboudy NA, Hussein HM. Assessment of in vitro anti-trichomonas vaginalis activity of deer musk. Int J Adv Res 2014;2:668-78.

6. AL-Jobori KM, AL-Khafagi NA, Witwit NM. Evaluation of the antagonistic effect of musk on eleven bacterial strains and three types of yeast. Topc J Microbiol 2014;2:1-6.

7. Saddiq AN, El-Elyani RA. Liver mycotoxicosis treated with musk and sidr extract. Egyptian J Exper Biol Egypt Tanata; 2009. p. 17-29.

8. Lai JH. Pharmacognosy. Taipei: Chuang-I Press; 1976. P. 541.

9. Oh SR, Lee JP, Chang SY, Shin DH, Ahn KS, Min BS, et al. Androstane alkaloids from musk of moschus moschiferus. Chem Pharm Bull 2002;50:663-4.

10. Thevis M, Schanzer W, Geyer H, Thieme D, Grosse J, Rautenberg $\mathrm{C}$, et al. Traditional Chinese medicine and sports drug testing: identification of natural steroid administration in doping control urine samples resulting from musk (pod) extracts. Br Sports Med 2013;47:109-14.

11. Sommer C. The role of musk and musk compounds in the fragrance industry. In: Series Anthropogenic Compounds. Springer, Berlin, Heidelberg; 2004. p. 1-16.

12. Leung AY. Encyclopedia of common natural ingredients used in food, drugs, and cosmetics. Wiley; 1980.

13. Kobayashi GS, Medoff G. Antifungal agents: recent developments. Annual Rev Microbiol 1977;31:291-308.

14. Saddiq AA, Kalifa SA. Impact of fungal content of some Arabic nuts to induce kidney toxicity and agonistic action of natural resources. Afr J Microbiol Res 2011;5:1046-56.

15. Pilz W. Der moschusduft-eine parfumhistorische betrachtung. SEPAWA Kongreßzeitschrift; 1997. p. 43-7

16. Kun Ying Yen. The illustrated Chines Materia Medica. Crude and Prepared. SMC Publishing Inc. Taipei, Taiwan; 1992. p. 383.
17. Gaski AL, Johnson KA. Prescription for extinction: endangered species and patented oriental medicines in trade/Andrea $\mathrm{L}$. Gaski, Kurt A. Johnson. Traffic USA; 1994.

18. Cheng DH, Jian WANG, Nan ZENG, XIA HL, Yong FU, Dan YAN, et al. Study on drug property differences of shexiang (moschus) and bingpian (borneolumsynthcticum) based on analysis of biothermodynamics. J Trad Chin Med 2011;31:21-6.

19. Yang $Q$, Feng $Z$. The status and the sustainable use of musk deer in China. The resource of vertebrate animals in Sichuan Sichuan Science and Technology Press: Chengdu; 1999.

20. Homes V. On the scent: conserving musk deer-the uses of musk and Europe's role in its trade. TRAFFIC Europe, Brussels, Belgium; 1999.

21. Saddiq AA. The use of musk as an antibiotic against fungi and yeasts. Patented, King Abdul Aziz City for Science and Technology. Riyadh, SA; 2004.

22. AL-Jobori $\mathrm{KM}, \mathrm{AL}-A m e e d \mathrm{AI}$, Witwit NM. In vitro antifungal activity of musk. Bull Environ Pharmacol Life Sci 2015;4:38-44.

23. Chateau L. Alternatives to antibiotics from nature. Jarir Bookstore, Saudi Arabia. Edn. 2; 2004. p. 29-36.

24. Reynolds JEF, Prasad AB, Shoutman SC. Martindal direction of the council of the pharmaceutical society Britain and prepared in the society,s department of pharmaceutical science. $31^{\text {st }}$ edition; 1996. p. 393960

25. Cowan MM. Plant products as antimicrobial agents. Clin Microbiol Rev 1999;12:564-82.

26. Elliott T, Worthington T, Osman H, Gill M. Medical microbiology and infection. (4th ed.) Blackwell Publishing Ltd., Oxford, U. K.; 2007.

27. Saddiq AAN. Antiagnostic effect of musk and sidr leaves on some of the opportunistic fungi that cause lung toxicity. Life Sci J 2014;11:99-108.

28. Ekwenye UN, Elegalam NN. Antibacterial activity of ginger (Zingiberofficinale Roscoe) and garlic (Allium sativum L.) extracts on Escherichia coli and Salmonella typhi. Int J Mol Adv Sci 2005;1:411-6.

29. Mottaleb MA, Brumley WC, Sovocool GW. Nitro musk metabolites bound to carp hemoglobin: determination by GC with two MS detection modes: EIMS versus Electron Capture negative ion MS. Int J Environ Anal Chem 2004;84:1069-78. 